\title{
Espaços Livres Públicos em Assentamentos Rurais: a Experiência do Rosário
}

\author{
ANDRADE, Sarah Andrade $\mathrm{e}^{1}$ \\ BORGES, Amadja Henrique ${ }^{2}$ \\ MEDEIROS, Cecília Marilaine Rego ${ }^{3}$ \\ CERQUEIRA, Maria Cândida Teixeira de ${ }^{4}$ \\ ${ }^{1}$ GERAH/PPGAU/UFRN, Natal/RN, Brasil-andradesarah22@gmail.com \\ ${ }^{2}$ GERAH/DARQ/UFRN, Natal/RN, Brasil. amadjaufrn@gmail.com \\ ${ }^{3}$ GERAH/PPGAU/UFRN, Natal/RN, Brasil. ceciliamarilaine@yahoo.com.br \\ ${ }^{4}$ GERAH/PPGAU/UFRN, Natal/RN, Brasil. mcandidac@gmail.com
}

\begin{abstract}
Resumo
Na parceria de mais de 20 anos entre o Grupo de Estudos em Reforma Agrária e Habitat (GERAH) e o Movimento dos Trabalhadores Rurais sem Terra (MST), diversas ações são empreendidas para a melhoria das condições de vida nos assentamentos rurais coordenados pelo Movimento, no Rio Grande do Norte. Permeando as intervenções do Grupo, a construção dos espaços livres públicos assume papel secundário pela falta de recursos a eles destinados no conjunto dos financiamentos dos habitats no campo. Explorando essa necessidade o GERAH, vinculado a outros grupos universitários, coordena o Programa de Extensão $O$ verso do reverso na construção do habitat do campo: gênero, participação e cidadania, com objetivo de realizar ações de formação técnica e social através da participação dos assentados na construção e gestão de espaços públicos, possibilitando o desenvolvimento e consolidação das áreas de assentamentos e seus espaços de sociabilidade. A construção coletiva da praça do Rosário, apropriada pela comunidade-alvo traz novas possibilidades para as 120 famílias do Rosário e para os demais assentamentos coordenados pelo MST, bem como para os envolvidos com a assessoria técnica e científica, que buscam a consolidação das relações entre a práxis e a teoria assim como entre o ensino, a pesquisa e a extensão.
\end{abstract}

Palavras-Chave: Espaços livres públicos, Mutirão, Habitat.

\begin{abstract}
In an over-20-year partnership between the GERAH/UFRN and the MST, several actions have been taken to improve living conditions in rural settlements coordinated by the Movement in Rio Grande do Norte. Permitting the interventions of the Group, the construction of public spaces has taken a secondary role due to the lack of resources allocated to them, in the set of financing of habitats in the field. Exploring this need the GERAH, linked to other university groups, has coordinated the Program "O verso do reverso na construção do habitat do campo: gênero, participação e cidadania", in order to carry out the actions of both social and technical training through the participation of the community in the construction and management of the public space, enabling the development and consolidation of settlement areas and their social areas as well. The collective construction of the Rosario Square, conquered by the community, brought new possibilities not only to 120 families in Rosario settlement but also to other settlements coordinated by the MST. Moreover it brought new possibilities to those involved in technical and scientific assistance who seek the consolidation of the relationship between praxis and theory as well as among teaching, research and extension.
\end{abstract}

Key-words: Public Spaces, "Mutirão", Habitat, participatory. 


\section{Introdução}

Ao longo dos mais de 20 anos de parceria entre o Grupo de Estudos em Reforma Agrária e Habitat (GERAH) e o Movimento dos Trabalhadores Rurais Sem Terra (MST), diversas ações são empreendidas com vistas à melhoria das condições de vida nos assentamentos rurais coordenados pelo Movimento no estado do Rio Grande do Norte. As atividades são desenvolvidas através de técnicas de planejamento participativo fundamentadas no método regressivoprogressivo ${ }^{1}$, na troca constante entre a teoria e a práxis, entre saberes científicos e populares e nas relações entre espaços concebidos e vividos. Baseia-se, sobretudo, nas contribuições de Karl Marx, desenvolvidas na França pelo filósofo Henri Lefebvre e, no Brasil, pelos pedagogos Paulo Freire e Carlos Brandão. As ações interdisciplinares do Grupo, introduzem a arquitetura e o urbanismo como mais uma área disciplinar da organização espacial dos assentamentos, requerendo, antes de tudo, a apreensão das particularidades do trabalho junto a um movimento social da envergadura do MST e o conhecimento de seus limites, enquanto assessoria. No entanto, visualiza-se as potencialidades desta parceria, ao possibilitar a espacialização do ideário do MST, através da metodologia do "Desenho do Possível" (BORGES \& MEDEIROS, 2012).

Apesar de permear todas as intervenções do GERAH nos assentamentos coordenados pelo MST, a construção dos espaços livres públicos, assume papel secundário devido à falta de recursos a eles destinados no conjunto dos financiamentos de seus habitats. Estes últimos, segundo Lefebvre (Raymond, 1966), ao serem

\footnotetext{
1 Método concebido por Marx e desenvolvido por Lefebvre no que se refere à produção do espaço. Trata de compreender um determinado fenômeno, partindo de seu momento presente em direção ao passado, não com a intenção de explicá-lo, mas, sobretudo, para esclarecer quais processos construíram, ou contribuíram para a construção do objeto em questão e, quais os apontamentos e possibilidades resultantes dessa análise para o futuro.
}

apropriados por seus moradores, tornam-se habitares, que integram a moradia a um espaço total constituído, dentre outros elementos, de espaços públicos.

Nos assentamentos rurais, no entanto, os equipamentos sociais de uso coletivo e seus espaços livres públicos são raros, dependendo de recursos parcos e esporádicos. Essa postura é assumida tanto pelo Instituto Nacional de Colonização e Reforma Agrária (INCRA), responsável pela demarcação do espaço físico do habitat, vias de circulação e implementação da infraestrutura básica nos assentamentos, quanto pela Caixa Econômica Federal (CEF) que passa a financiar suas moradias a partir de 2003.

Enquanto o vivido nos acampamentos do Movimento passa pelo embelezamento de suas áreas coletivas, utilizando-se de materiais naturalmente disponíveis e do trabalho voluntário dos próprios assentados, sua construção quase nunca acontece simultânea e articuladamente à construção das moradias, já nos assentamentos, quando há recursos para os mutirantes envolvidos nas obras.

Segundo Boggo (2001) os acampados são águias que se transformam em galinhas ao se tornarem assentados, ciscando por cada migalha dos - parcos - créditos que passam a receber. Para a construção de seus habitats não há recursos para espaços públicos nos assentamentos rurais. No entanto, nas experiências assessoradas pelo GERAH, estes são propostos no desenho do assentamento, só que exige o trabalho voluntário, 0 uso de materiais sem custo de aquisição, fruto de projetos específicos de universidades, ONG, dentre outros, visto que o Crédito Habitação ou similar é exclusivo para a construção de moradias.

\subsection{Objetivos}

Explorando essa necessidade o GERAH, vinculado o Departamento de Arquitetura e Urbanismo (DARQ) da Universidade Federal do Rio Grande do Norte (UFRN) se articulou aos grupos universitários "Gênero Corpo e Sexualidade" (GCS-DAN) e "Grupo de Estudos 
e Práticas Educativas em Movimento" (GEPEM) para a criação do Programa de Extensão financiado pelo MEC-SESU, que possibilitou a experiência da construção coletiva da praça do Assentamento Rosário, no município de Ceará Mirim/RN. Denominado O verso do reverso na construção do habitat do campo: gênero, participação e cidadania, o Programa teve como objetivo realizar ações de formação técnica e social e através da participação dos assentados na construção e gestão de um espaço público, possibilitando o desenvolvimento e consolidação das áreas de assentamentos e seus espaços de sociabilidade.

A parceria com o MST inicialmente elegeu desenvolver tal experiência no Assentamento Roseli Nunes, no município de lelmo Marinho/RN, onde já tinham sido construídas moradias em regime de mutirão assistido, em conjunto com a assessoria do GERAH. A escolha, que parecia consolidar as relações de cooperação entre os agentes do processo, evidenciou, no entanto, conflitos nas relações entre assentados, Movimento e assessoria, que se traduziram na ausência de participação e comprometimento da comunidade nas oficinas. Durante alguns meses, a parceria lutou para contribuir com a superação dos conflitos - por meio de visitas semanais, esquetes teatrais, debates, encontros, festividades e reuniões - que acabaram por ultrapassar as possibilidades da assessoria e definiram a descontinuidade da experiência naquele assentamento.

A partir de então, os proponentes do Programa, seus bolsistas e a entidade organizadora iniciaram uma avaliação das possibilidades de mudança da proposta para outro assentamento, resultando em negociações e posterior compromisso com os moradores do assentamento Rosário. Estes já apresentavam a demanda por espaços de lazer para os jovens - identificada através de enquete preparatória para 6을 Congresso Nacional do $\mathrm{MST}^{2}$, realizada

\footnotetext{
2 Realizado em fevereiro de 2014, em Brasília.
}

e aplicada com os próprios assentados.

Assim, para cumprir o objetivo geral do Programa, referido anteriormente, uma série de objetivos específicos foi desenvolvida como: 1) O desenvolvimento de oficinas de capacitação de mulheres com o enfoque de gênero realizadas pelo grupo vinculado ao Departamento de Antropologia DCCS-DAN; 2) A continuidade da assessoria técnica e científica da UFRN, através do GERAH, na finalização da reforma de moradias do Rosário, inserindo espaços de sociabilidade, permanência e convivência; 3) A viabilização de projetos de organização do habitat; 4) 0 favorecimento de espaços de reflexão acerca da cidadania e participação coletiva.

Com sua filosofia e definições devidamente apropriadas por seus participantes, o plano de atuação começou a ser elaborado através da discussão sobre as demandas da comunidade e os limites e possibilidades contempladas pelo edital do Programa. Nessa ocasião, foi definido o programa de necessidades da obra: uma praça com percurso para caminhadas, bancos, brinquedos e espaço destinado à futura implantação de uma academia da terceira idade; um campo de futebol e campo de vôlei de areia; a arborização das principais áreas de permanência, e a reforma de um equipamento abandonado (ver figura $6 \mathrm{H}$ ), para abrigar uma biblioteca.

$\mathrm{O}$ ato de habitar extrapola o entendimento da mera moradia como invólucro físico, cuja principal função é a de abrigo. A célula habitacional é apenas uma parte do habitat, que deve ser entendido como tudo aquilo que circunscreve a vida do ser humano, aí incluídos os serviços e equipamentos urbanos, os meios de locomoção, as condições de localização, os costumes e hábitos de morar e as representações sociais.

Em definição da FAO - Organização das Nações Unidas para Agricultura e Alimentação, o habitat deve ser entendido como o somatório dos espaços onde o homem realiza suas atividades cotidianas, sejam elas atividades produtivas, de serviços, residenciais ou de bem 
estar geral (FAO, 1975, apud PERES, 2003, p. 86).

A habitação rural, por sua vez, pode ser definida como o modo de ocupação do solo em vista da exploração agrícola. Nesse sentido, "os estudos do habitat rural abrangem todos os elementos do estabelecimento rural: a casa, as dependências de serviço, além do conjunto dos campos de cultura, pastagens, hortas, jardins, estradas, caminhos, etc." (COSTA, 1995, p. 5).

A casa pode ser considerada o elemento central do habitat rural, pois além de servir de moradia, a habitação rural abrange outras funções além da residencial, com a de armazenagem, e, até mesmo, de beneficiamento da produção. Nesse sentido, ela representa a sede de uma exploração rural, sendo portanto um importante elemento de organização do meio rural. Com esta conotação, a casa rural reflete na organização do espaço a estratificação social.

Dada a extensão territorial do Brasil e as peculiaridades geográficas, culturais e econômicas, a habitação rural apresenta enorme variedade de tipos, que os autores classificam em função da atividade econômica dominante - o complexo açucareiro, as fazendas de café, as fazendas de cacau, as casas dos seringais -, ou a partir da localização geográfica - casas rurais amazônicas, sulinas, do pescador nordestino, dos colonos açorianos, etc. (COSTA, 1978, p. 9).

O tema abordado neste trabalho liga-se à casa do pequeno proprietário rural em Minas Gerais, com a finalidade de avaliar a adequação das tipologias que vêm sendo adotadas pelo Programa Nacional de Habitação Rural - PNHR ao modo de morar no campo.

Para tanto, procurou-se inicialmente caracterizar a casa rural mineira, tanto numa perspectiva histórica e sociológica quanto sob o aspecto construtivo. Entretanto, considerandose a extensão territorial do Estado e suas diferenciações regionais, optou-se por adotar como recorte espacial a Zona da Mata mineira.

Em seguida, apresentam-se os objetivos e diretrizes do PNHR, focando nas especificações mínimas previstas para as moradias rurais.

Por fim, procura-se estabelecer um contraponto entre o modo de vida característico da população que vive na área rural da Zona da Mata mineira e o modelo de casa que vem sendo adotado pelo PNHR em municípios da região.

\section{Procedimentos metodológicos}

Dando prosseguimento ao plano de atuação, buscou-se áreas que comportassem o programa de necessidades definido na etapa anterior, considerando espaços que possibilitassem a execução dos sonhos dos assentados e também aqueles que já fizessem parte de seu cotidiano, articulando espaço vivido e concebido (Lefebvre, 1945). Chegouse, assim, à sugestão de uma área contígua às residências (ver figura 1), com equipamentos pré-existentes e onde, apesar da falta de estrutura, já se davam práticas cotidianas de lazer e sociabilidade da comunidade.

Figura 1: Localização da área de intervenção com seus respectivos equipamentos.

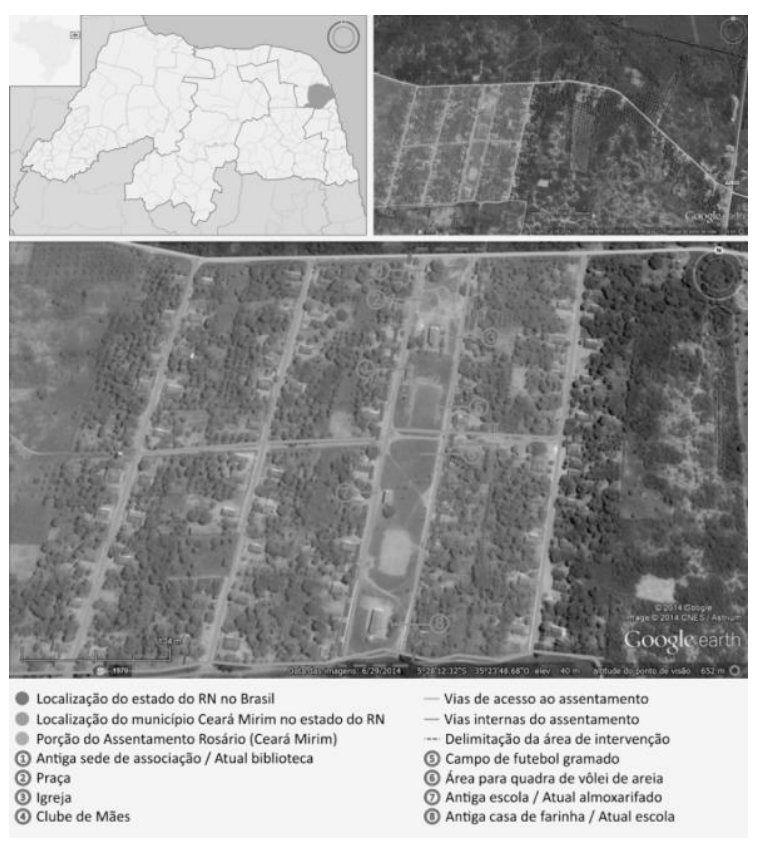

Fonte: GoogleEarthWikipédia

(http://pt.wikipedia.org/wiki/Cear\%C3\%A1Mirim\#mediaviewer/File:Rio GrandedoNorte_Municip_Ceará Mirim.svg), acessados em agosto de 2014, modificados pelas autoras em setembro de 2014 .

Quanto às atividades dirigidas pelo GERAH, denominadas de construção do habitar, metodologicamente, a etapa que se seguiu foi a elaboração dos projetos, coletivamente 
discutidos (figura $6 \mathrm{C}$ ), e das oficinas de capacitação para sua construção. Inicialmente foram apresentadas referências (figura 2) de intervenções em espaços públicos, no campo e na cidade, todas concebidas e executadas de forma coletiva, com materiais não convencionais, na tentativa de criar e/ou ampliar o repertório das possibilidades de atuação da comunidade organizada.

Em seguida foram organizadas quatro oficinas de capacitação para apreensão e aplicação das técnicas não convencionais: 1) A oficina de construção de calçadas com meio fio em garrafa PET (figura 6 A e B); 2) A oficina de construção de bancos com pneus (figura $6 \mathrm{D}$ ); 3) A oficina de construção de brinquedos e arquibancadas com pneus (figura 6 F) e 4) A oficina de arborização das áreas de permanência (figura $6 \mathrm{G}$ ).

Tais oficinas foram divididas em duas etapas: inicialmente os integrantes do GERAH apresentaram a técnica construtiva proposta para cada momento do projeto, com auxílio de painéis e desenhos esquemáticos (figura 3), incorporando as sugestões e discutindo as dificuldades encontradas pelos assentados. Posteriormente, em momento e carga horária acordados entre os integrantes do grupo, deuse a continuidade da execução da atividade objeto da oficina, acompanhada pelos "oficineiros locais" - militantes do próprio assentamento -, utilizando as técnicas trabalhadas na primeira etapa.

Os postos de "oficineiros locais" e seus coordenadores no assentamento foram definidos nas primeiras oficinas de elaboração do plano de atuação, em comum acordo entre os dirigentes e assentados mais engajados, pertencentes às diversas associações do Rosário. Estas últimas surpreenderam a equipe pela dedicação ao projeto e pela parceria com o MST, que possibilitou a continuidade dos trabalhos, mesmo com a limitada e decrescente participação das famílias no processo.
O encaminhamento dado às oficinas se afina com as bases metodológicas da assessoria técnica, contribuindo para o engajamento da comunidade no processo de construção, sem distinção de idade e gênero, fortalecendo o sentimento de pertencimento à experiência como beneficiário/usuário e, principalmente, como agente efetivo do processo, rompendo a "relação tradicional de sujeito-objeto, entre investigador-educador e os grupos populares, sendo progressivamente convertida em uma relação do tipo sujeito-sujeito, a partir do suposto de que todas as pessoas e todas as culturas são fontes originais de saber." (BRANDÃO E BORGES, 2007, p.54).

Após 22 meses de trabalho conjunto entre assessoria técnica, lideranças e bases do MST, as atividades no assentamento Rosário trouxeram o enfrentamento de uma série de dificuldades, o desenvolvimento de inúmeras reflexões e críticas e o vislumbre de um conjunto de desdobramentos e possibilidades futuras de atuação. O Grupo considera ter atingido seus objetivos já que quase tudo se passou como planejado, com o engajamento dos grupos e do principal parceiro, o MST responsável pela organização do público-alvo e da sua participação nas oficinas.

Figura 2: Capa do material produzido pelo GERAH para apresentação de referências de embelezamento de assentamentos com exemplo de placa de comunicação visual da Agrovila 5, no assentamento Pirituba II (Itapeva,

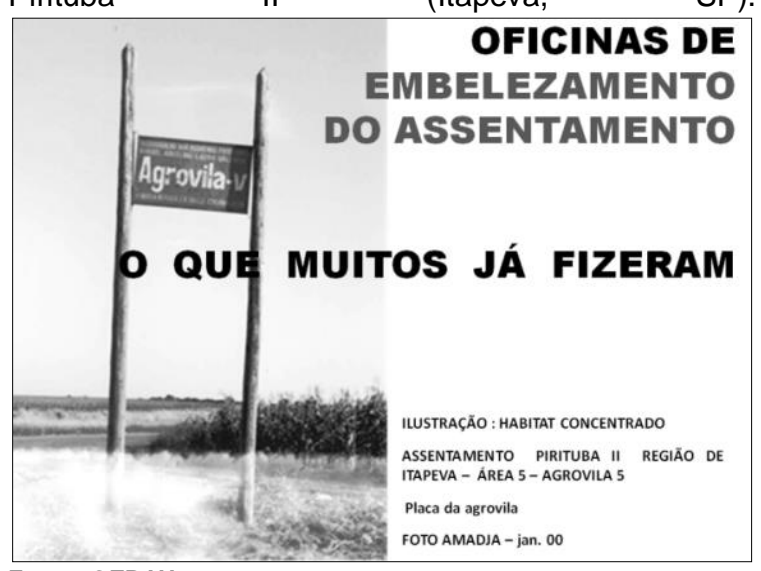

Fonte: GERAH. 
Figura 3: Exemplo de painéis desenvolvidos para as oficinas (bancos) do GERAH.
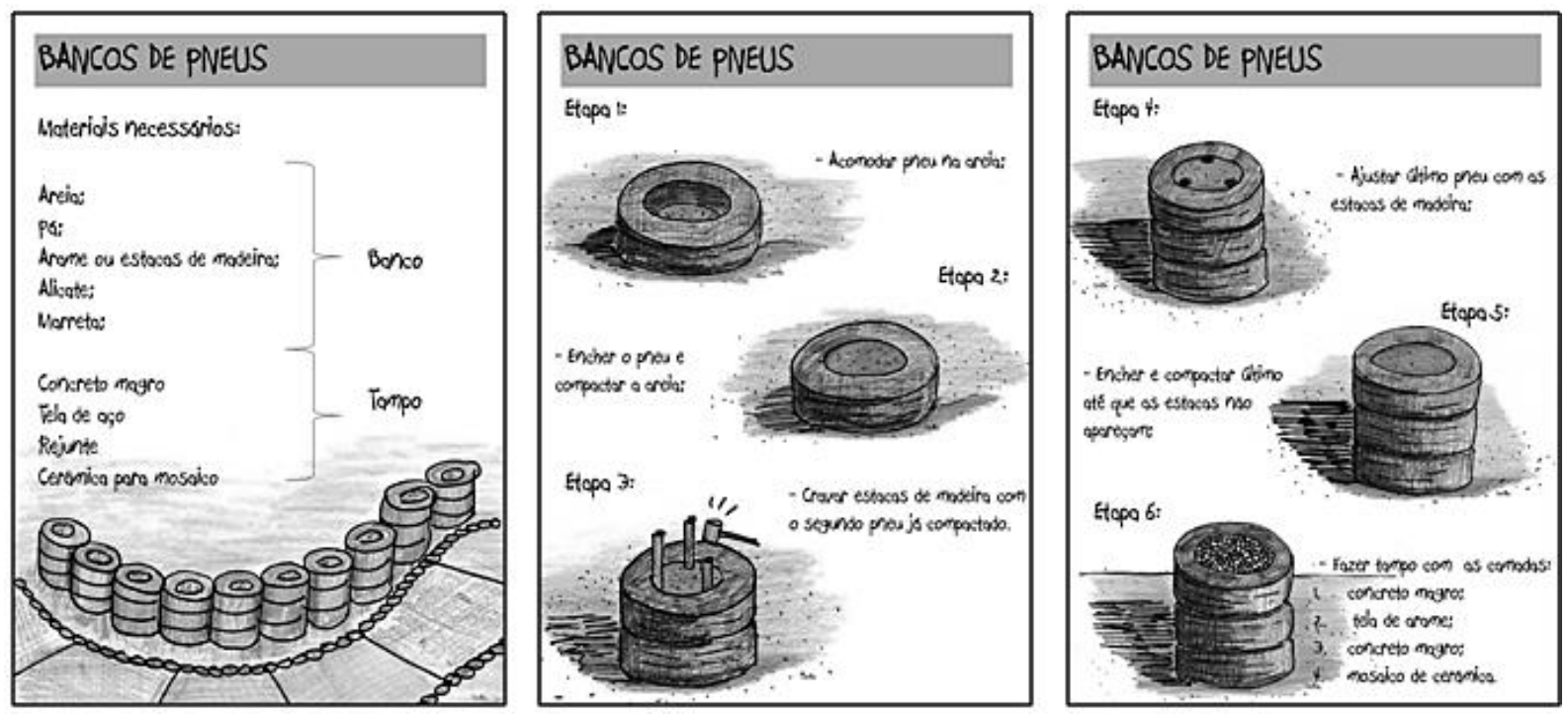

Fonte: GERAH.

\section{Resultados e Discussão}

Os conflitos que inviabilizaram a realização da proposta no local inicialmente escolhido abriram a possibilidade de atender a outra comunidade que, antes mesmo de ter conhecimento deste programa e de seus objetivos, já registrava o ressentimento de seus moradores com a falta de espaços de lazer, encontros, esportes e cultura, diante do isolamento do cotidiano de suas 120 famílias, o que afligia, sobretudo, aos jovens.

Por outro lado, a efetivação das ações planejadas no contexto de um Programa de Extensão de iniciativa universitária, esteve condicionada a duas lógicas temporais diferentes. A primeira delas, a lógica do tempo burocrático, institucional, o tempo de início e fim do edital do projeto e todas as implicações decorrentes disto, desde os prazos de submissão dos relatórios e prestação de contas, até o acesso ao sistema (e recursos) para a compra de material de construção e a disponibilidade de cotas para bolsistas. Já a segunda, a do tempo do projeto participativo, tem andamento quase sempre diferente da primeira, devido à proposta metodológica adotada, que enfatiza momentos de discussão e reflexão (o processo mais do que o resultado final), pela reunião de um grupo heterogêneo de trabalho (o que demanda mais tempo de articulação, planejamento e afinação de ideias) e, ainda, pelos percalços e conflitos inevitáveis e a elaboração de estratégias para contorná-los.

Sobre a articulação entre os diversos vieses do Programa, observa-se a defasagem entre 0 processo construtivo e o de gênero, havendo um distanciamento gradativo das mulheres, o que implicou, ao final da experiência, na sua reclamação quanto à ausência de um "espaço delas" (que seria o campo de vôlei de areia, não finalizado pela falta de material para composição do alambrado de delimitação, no sistema de compras da Universidade). Os homens, ao contrário, sentiram-se contemplados com a construção do campo de futebol (figura $6 \mathrm{~K}$ ), articulando-se para agilizar sua estruturação, viabilizando, inclusive, a doação do gramado e a bomba para auxílio de sua irrigação.

Apesar dos limites, considera-se que houve uma interação entre as atividades de ensino, pesquisa e extensão, das ciências humanas às ciências sociais aplicadas, do saber tecnológico ao saber tradicional e popular e, também, à inclusão dos trâmites burocráticos necessários para tornar possível o caminho escolhido. Ao buscar formas não convencionais da construção civil, abriram-se possibilidades de apropriação pelas camadas populares da classe trabalhadora de novas áreas de convivência em suas áreas livres públicas, como o local da caminhada, do exercício, do encontro e das 
manifestações culturais.

Esta experiência também trouxe a síntese do sentido da ação e na compreensão de que estudantes e militantes envolvidos também podem ousar, descobrir, aplicar conhecimentos inovadores para assentamentos humanos, sem muitos recursos financeiros e ainda, mostrouIhes um nicho de atuação profissional ainda pouco explorado, sobretudo para o arquiteto e urbanista no campo, ou para os militantes do campo na construção de espaços de lazer e entretenimento.

Atuar na área rural, especificamente com comunidades que conquistaram na luta pela reforma agrária o direito à cidadania, contribuiu, também, na consolidação dos assentamentos do campo, ao atender à melhoria das condições de vida, no que concernem seus espaços de convívio e festa.

Conforme demanda identificada pelo MST, a equipe do Programa dirigiu seus principais esforços às novas gerações, que nem sempre passaram pelo processo de conquista de seus habitats, como seus pais. Como exemplo de atividades nesse sentido a "Festa da Cumeeira" (ver figura 4), no Assentamento Roseli Nunes (município de lelmo Marinho) e o encontro "Entre Pedras e Flores" (ver figura 5), no Assentamento Rosário (município de Ceará Mirim), resgataram a origem e o valor daqueles que conquistaram cada uma das duas comunidades estudadas através de discussões sobre seus momentos de conflito e conquistas, com apresentação de filmes, fotos, vídeos e encenações.

Nesse sentido, a construção coletiva da Praça do Rosário, apropriada pela comunidade-alvo trouxeram novas possibilidades para as 120 famílias do assentamento e para os demais assentamentos coordenados pelo MST e entidades aliadas às duas outras associações locais. A visibilidade da experiência ultrapassou as expectativas iniciais, ganhando destaque pelas redondezas devido à nova configuração paisagística da praça, o que despertou 0 interesse de moradores de outros assentamentos e acampamentos em visitá-la e em reproduzir as práticas ali desenvolvidas, o que multiplica quantitativamente sua abrangência.

Figura 4: Momentos da Festa da cumeeira no Assentamento Roseli Nunes.
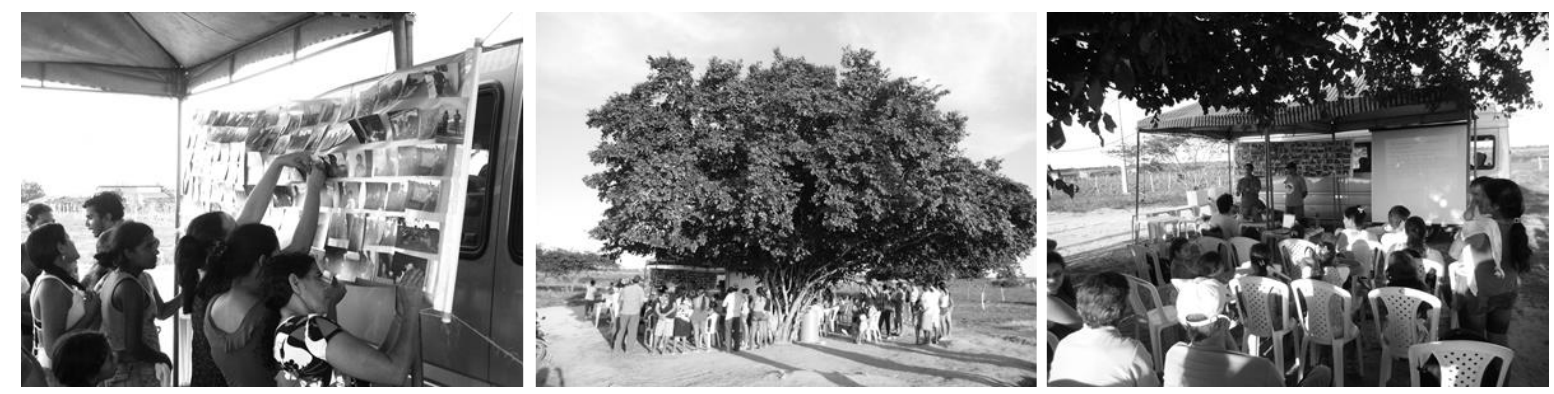

Fonte: GERAH, 2012. 
Figura 5: Momentos do encontro Entre pedras e Flores, no Assentamento Rosário.
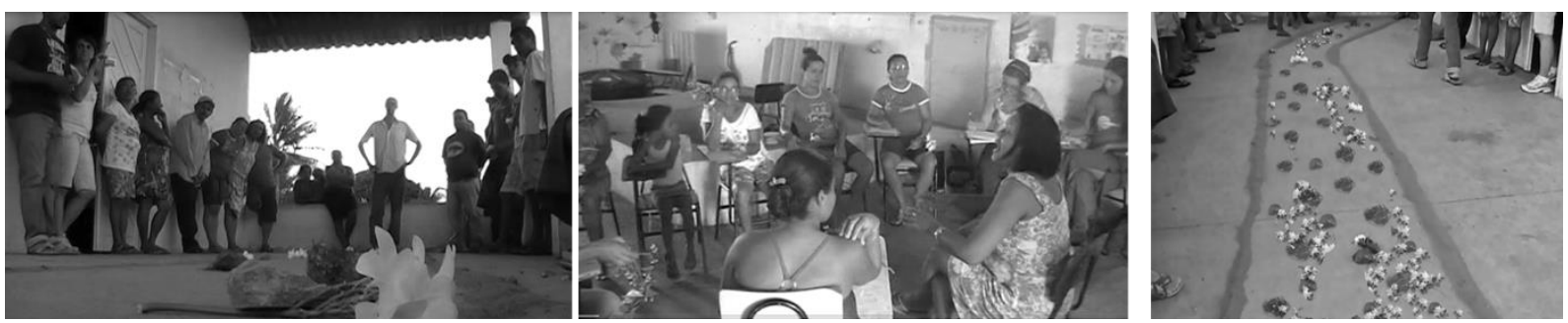

Fonte: GERAH, 2012.

Figura 6: Momentos do encontro Entre pedras e flores, no Assentamento Rosário.
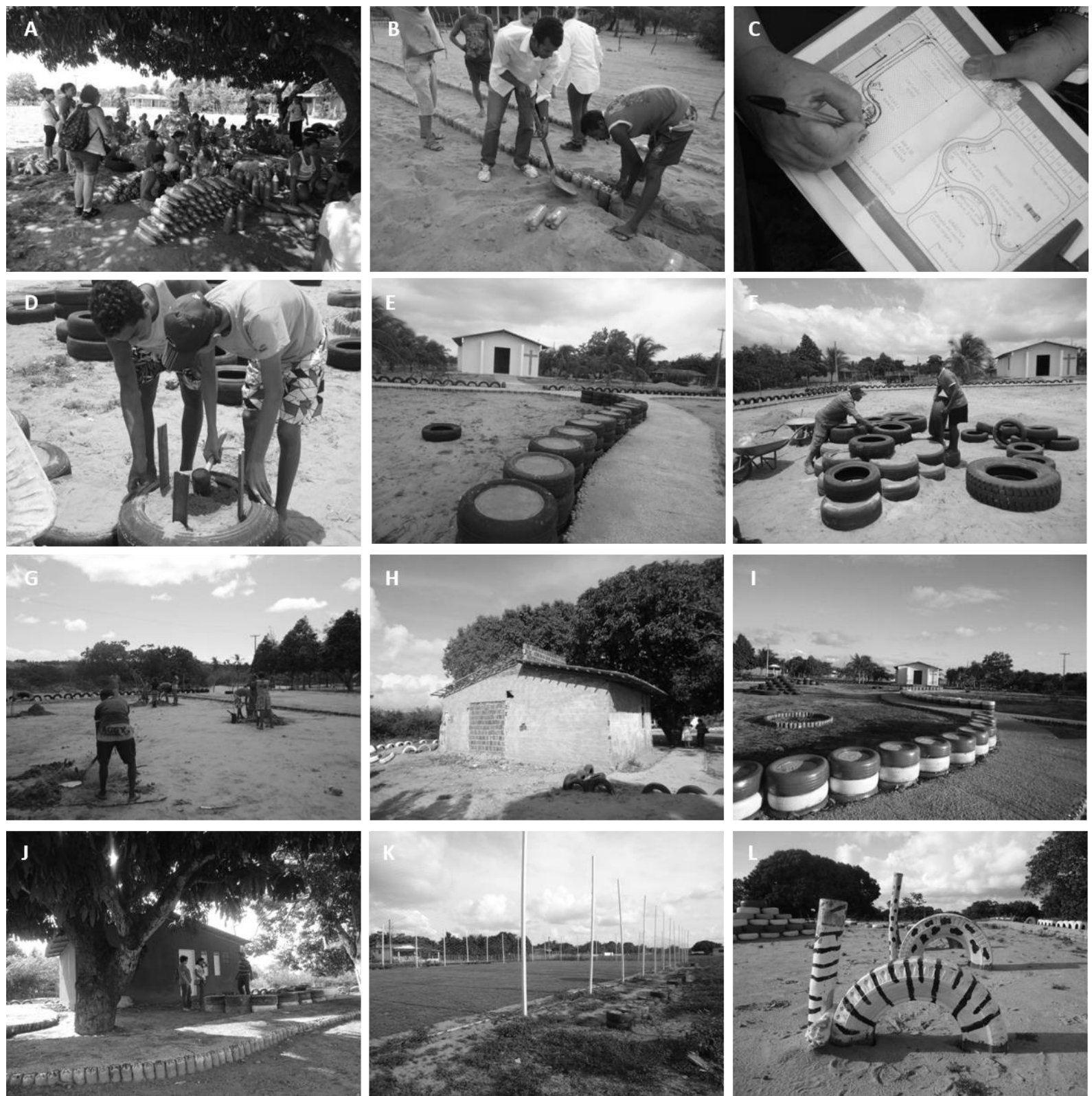

Fonte: GERAH, 2012, 2013, 2014. 


\section{Conclusão}

Como desdobramentos desta ação para o GERAH e seus colaboradores, vê-se a continuidade da assessoria técnica e científica, com a inserção dos espaços de sociabilidade e de permanência além da convivência familiar, de acordo com as escolhas coletivas. Estas especificidades favoreceram espaços de reflexão acerca da cidadania e participação coletiva, intensificados pelas dinâmicas políticoavaliativas dos participantes das áreas sociais de conhecimento e da própria direção e militância dos parceiros.

A contribuição das duas outras associações convidadas pelo movimento parceiro no Assentamento, também expressa que nele existe uma articulação interna para determinadas ações, com potencialidades de avançar e romper novas barreiras. A praça, seus equipamentos, a compreensão de cidadania e participação assim como o respeito aos direitos de todos os seus grupos sociais, como uma obra, não pode ser considerada finalizada. Mas as condições foram estabelecidas para que suas lideranças e bases desenvolvam esse ambiente de convívio e cidadania.

É desejado ainda, o engajamento de outros grupos, através das possibilidades de atuação lançadas pelo $\mathrm{O}$ verso do reverso, tanto na formação do acervo e organização da biblioteca, como nas atividades esportivas e artístico-culturais no local, dentre outros, de acordo com as contribuições que novos programas e projetos extensionistas possam trazer.

Por fim, a semente foi lançada também para os moradores (que têm na experiência, o exemplo da busca pela troca de conhecimentos), para os envolvidos com a assessoria técnica e científica (que buscam a relação entre a práxis e a teoria; entre o ensino, a pesquisa e a extensão), enquanto não se conquista uma política específica para a consolidação dos espaços de lazer, de encontro e de cidadania nos assentamentos do campo, pois, ao se buscar a transformação do habitat em habitar na concepção de Lefebvre (1978, p. 171-172), tem- se que:

\begin{abstract}
O que desejam os seres humanos, em essência seres sociais, no habitar? Desejam um espaço flexível, apropriável, tanto na escala da vida privada quanto naquela da vida pública, da aglomeração e da paisagem. Tal apropriação necessita partir do conceito de espaço social, assim como daquele de tempo social. O espaço social não coincide com o espaço geométrico e a qualidade especifica dele vem de uma apropriação. Quando essa apropriação desaparece, o espaço social e o espaço geométrico coincidem, do mesmo modo que o tempo social e aquele dos relógios. Na direção de quem, portanto, se orientam os desejos dos interessados? $\mathrm{Na}$ direção de uma nova concepção de habitar que responder as exigências da técnica e de vastas aglomerações modernas sem, no entanto, sacrificar a qualificação, as diferenças e a apropriação espaçotemporais... Na direção de quem, portanto, se orientam os desejos dos interessados? $\mathrm{Na}$ direção de uma nova concepção de habitar que responder as exigências da técnica e de vastas aglomerações modernas sem, no entanto, sacrificar a qualificação, as diferenças e a apropriação espaço-temporais.
\end{abstract}

\section{Referências}

BOGO, Ademar. O MST e a cultura. (MST: Caderno de formação n. 34). 2a. ed. Veranópolis: ITERRA, 2001.

BORGES, Amadja Henrique (Coord.). O verso do reverso na construção do habitat do campo: gênero participação e cidadania. Relatório de programa extensão. Pró-reitoria de extensão. Universidade Federal do Rio Grande do Norte, Natal. 2013.

BORGES, Amadja Henrique. MST: habitats em movimento: tipologias dos habitats dos assentamentos originários do MST nos estados de SP e RN. Tese de doutorado - FAU/USP. São Paulo, 2002.

BORGES, Amadja Henrique. Necessidades, expectativas e sonhos no desenho do possível: proposta metodológica de organização do espaço físico-territorial dos assentamentos do Movimento dos Trabalhadores Rurais Sem Terra. Projeto de Pesquisa. Pró-reitoria de pesquisa. Universidade Federal do Rio Grande do Norte, Natal, 2005.

BORGES, Amadja Henrique. O desenho do 
possível: a UFRN e o MST na construção de um projeto-referência de assentamento de reforma agrária. In: Ilza Araújo Leão de Andrade (Org.). Metodologia do trabalho social: a experiência da extensão universitária. 1. ed. Natal: EDUFRN, 2006.

BORGES, Amadja Henrique; MEDEIROS, Cecília Marilaine de. O verso do reverso na integração entre as atividades-fim da universidade. In: COSTA, Fernando José de Medeiros (Org.). Anais XXXI ENSEA/XXXV COSU: Novos cenários para o ensino da arquitetura e urbanismo: atualizar, avaliar, acreditar. São Paulo, 37ํㅡㄹ Cadernos ABEA, 104117, nov. 2012. Disponível em: <http://issuu.com/gogli/docs/caderno_37/56>.

Acesso em: 04 mar. 2015.

BORGES, Amadja Henrique; MEDEIROS, Cecília Marilaine Rêgo de; OLIVEIRA, Márcia. Silva; ANDRADE, Sarah de Andrade e. Possibilidades de apropriação do habitat em assentamentos rurais no Brasil. In: Anais da I Conferência Latino-Americana e Européia sobre Edificações e Comunidades Sustentáveis, 2015, Guimarães. Luis Bragança, Andrea Naguissa Yuba, Cristina Engel de Alvarez, 2015. v. 2. p. 863-872.

Disponível

em: http://civil.uminho.pt/euro-elecs-2015/files/EuroELECS_2015-Proceedings_Vol2.pdf>. Acesso em: 05 maio. 2016.

BRANDÃO, Carlos R. (Org.). Pesquisa participante. 4. ed. São Paulo: Brasiliense, 1981.

BRANDÃO, Carlos Rodrigues; BORGES, Maristela Correa. A pesquisa participante: um momento da habitação popular.Revista de Educação Popular. Uberlândia, v. 6, n. 1, p.5062, dez. 2007. Disponível em: <http://www.seer.ufu.br/index.php/reveducpop/a rticle/view/19988/10662>. Acesso em: 06 mar. 2015.

CERQUEIRA, Maria Cândida Teixeira de. A assistência técnica nos habitats do MST e o papel do arquiteto e urbanista. Dissertação (Mestrado em Arquitetura e Urbanismo) - PPGAU/UFRN, 2009.
GOMES, Ana Paula Freitas. Um estudo etnográfico sobre a participação feminina no assentamento Rosário - Ceará Mirim. Monografia. Curso de Ciências Sociais. UFRN, 2013.

Grupo de Estudos Em Reforma Agrária e Habitat. Departamento de Arquitetura da Universidade Federal do Rio Grande do Norte. Vamos embelezar juntos 0 assentamento Rosário? Natal: Grupo de Estudos em Reforma Agrária e Habitat, 2012. 38 slides, color, $25 \times$ $19,04 \mathrm{~cm}$.

LEFEBVRE, Henri. Critique de la vie quotidienne: Introduction.1ère ed., Paris: L'Arche Éditeur, 1945.

LEFEBVRE, Henri. De lo rural a lo urbano. $4^{\mathrm{a}}$ ed., Barcelona: Península, 1978.

MEDEIROS, Cecília Marilaine Rego de. Arquitetura da terra e transformação das referências de morada do MST. Monografia Curso de Arquitetura e Urbanismo, Departamento de Arquitetura, Universidade Federal do Rio Grande do Norte, Natal, 2009.

MEDEIROS, Cecília Marilaine Rego de. Mutirão $X$ Organicidade: Reflexões sobre os processos de construção coletiva dos habitats dos assentamentos rurais coordenados pelo MST no RN. Dissertação (Mestrado) - Curso de Arquitetura e Urbanismo, Universidade Federal do Rio Grande do Norte, Natal, 2013.

PAIVA, Irene A. Aprendizados da prática coletiva: assentados e militantes do MST. 2003. Tese (Doutorado em Educação) - Programa de Pós-Graduação em Educação da Faculdade de Educação da Universidade de São Paulo, 2003.

SCHWADE, Elisete. Gênero e juventude em assentamentos rurais. In: Schwade, Elisete \& Valle, Carlos Guilherme (org.). Processos Sociais, Cultura e Identidades. São Paulo: Annablume, 2010.

SILVA JÚNIOR, Ramiro Teixeira da. Organização dos trabalhadores do Campo: uma experiência na Associação Nova Esperança em Ceará Mirim/RN. Monografia. Curso de Ciências Sociais. UFRN, 2013. 